\title{
The presence of serum anti-Ascaris lumbricoides IgE antibodies and of Trichuris trichiura infection are risk factors for wheezing and/or atopy in preschool-aged Brazilian children
}

\author{
Neuza M Alcântara-Neves ${ }^{1 *}$, Samuel J Badaró ${ }^{1}$, Mariese CA dos Santos ${ }^{1}$, Lain Pontes-de-Carvalho ${ }^{2}$,
} Maurício L Barreto ${ }^{3}$

\begin{abstract}
Background: The elucidation of factors that trigger the development of transient wheezing in early childhood may be an important step toward understanding the pathogenesis of asthma and other allergic diseases later in life. Transient wheezing has been mainly attributed to viral infections, although sensitisation to aeroallergens and food allergens may occur at an early age. In developing countries, intestinal helminthic infections have also been associated with allergy or atopy-related disorders.
\end{abstract}

Objective: The aim of this study was to explore the association of Trichuris trichiura and Ascaris lumbricoides infections with wheezing and atopy in early childhood.

Study design: A cross-sectional study using a Portuguese-language ISAAC phase I questionnaire, adapted for preschool-aged children, nested in a cohort study of childhood diarrhoea, was conducted on 682 children. Two faecal samples per child were examined for the presence of intestinal helminthic infection. IgE antibodies against three allergenic preparations (Dermatophagoides pteronyssinus, Blomia tropicalis and common child food), as well as against $A$. lumbricoides antigens, were measured in a sub-sample of these children, whose parents allowed the procedure. Atopy was defined by the presence of levels of serum IgE antibodies $\geq 0.35 \mathrm{kU} / \mathrm{L}$ against at least one of the three tested allergenic preparations.

Results: Active T. trichiura infection but not A. lumbricoides infection was positively associated with wheezing in the total studied children population [adjusted $\mathrm{OR}=2.60 ; \mathrm{Cl}=1.54 ; 4.38$ ] and in the atopic children sub-population [adjusted $\mathrm{OR}=3.07 ; \mathrm{Cl}=1.00 ; 9.43]$. The association with atopy was also positive and statistically significant only in the brute analysis $[\mathrm{OR}=2.13 ; \mathrm{Cl}=1.03 ; 4.40]$. Anti-A. lumbricoides IgE antibodies, but not current $\mathrm{A}$. lumbricoides infection, were positively associated with wheezing in atopic children [adjusted $\mathrm{OR}=2.01 ; \mathrm{Cl}=1.00 ; 4.50$ ] and in non-atopic children [adjusted $\mathrm{OR}=3.07 ; \mathrm{Cl}=1.13 ; 8.35$ ] and it was also associated with atopy [adjusted $\mathrm{OR}=7.29$; $\mathrm{Cl}=3.90 ; 13.4]$. On the other hands, reports of wheezing were not significantly associated with atopy.

Conclusions: These data corroborate previous studies showing that wheezing is predominantly associated with infection in early childhood and shows that anti-A. lumbricoides IgE antibodies, but not active Ascaris infections, are associated with wheezing and atopy. Additionally, the data demonstrate that T. trichiura infection may play a role in the pathogenesis of atopic wheezing in early childhood.

\footnotetext{
*Correspondence: neuza@ufba.br

'Departmento de Ciências da Biointeração, Instituto de Ciências da Saúde,

Universidade Federal da Bahia, Salvador, Brazil

Full list of author information is available at the end of the article
} 


\section{Introduction}

The pathogenesis of allergy is multifactorial, depending on both the individual's genetic background and environmental factors. The prevalence and incidence of allergic diseases are increasing worldwide, particularly in the urban populations of developed countries. The International Study of Asthma and Allergies in Childhood (ISAAC), conducted in several Brazilian cities, showed that the city of Salvador, where the present work was completed, had a very high prevalence $(24.0 \%)$ of wheezing among children [1]. Among the environmental factors that may trigger allergic diseases, infections are the most studied. Surprisingly, helminthic infections, which induce the host immune system to mount $\mathrm{T}$ helper 2 (Th2) immune responses, as during an allergic reaction, have been negatively associated with atopy and allergic illness $[2,3]$. In spite of the evidence that helminths protect their hosts against allergy, some studies have indicated that infection by these parasites does not affect allergy or atopy $[4,5]$, while others have demonstrated a positive association of these infections with atopy as well as with asthma and rhinitis [6,7]. Worm burden and the timing of infection seem to play a role in the relationship between parasite infection and the host immune response [8]. Recently, our research group demonstrated that infection by Trichuris trichiura during early childhood was negatively associated with the development of aeroallergen skin test reactivity in later childhood [9]. In the present work, we report that Ascaris lumbricoides sensitisation and T. trichiura infection, but not $A$. lumbricoides infection, were associated with wheezing in early childhood. In addition, $A$. lumbricoides sensitisation was also strongly associated with atopy.

\section{Materials and methods Study population}

The study population was part of a cohort of 1283 children, born from 1998 to 2000, and recruited between 2000-2001, living in 24 small geographical areas (also called sentinel areas) in Salvador, a major city in the northeast of Brazil. These children were originally selected for a study to evaluate the impact of a sanitation program on the incidence of childhood diarrhoea $[10,11]$ and were followed up to 2002 . The populations of these areas are of low socioeconomic status and similar ethnicity. The present data were collected from a randomly selected sub-sample of 683 children enrolled in the cohort, all of them were less than five years old (average age of 2.3 years, range from $1-4.2$ years). This sub-sample size was estimated assuming a $22 \%$ prevalence for wheezing and a $25 \%$ prevalence for infection by intestinal helminthes, based on on-going studies carried out on children of the same city, with $3 \%$ precision and 95\% confidence. Demographic and social data were collected using a validated questionnaire. The children were visited twice per week for one year to collect information on the occurrence of diarrhoea. At the end of the study, a Portuguese-language ISAAC phase I questionnaire, adapted for young children, was administered to the children's parents or guardians by trained interviewers. Two stool samples were collected two days apart and examined for parasitic infections. Blood was collected from a subgroup of 283 children whose parents agreed to the procedure. Serum aliquots prepared from the blood samples were stored at $-70^{\circ} \mathrm{C}$ until use. The sera were then assessed for IgE antibodies against house dust mites, common childhood food allergens (milk, ovalbumin and peanut) and A. lumbricoides antigens. All parasite-infected children received anti-helminthic and anti-protozoan treatment and were sent for ambulatory treatment during episodes of asthma and diarrhoea. Ethical approval was granted by the Ethical Committee on Research of the Instituto de Saúde Coletiva, Universidade Federal da Bahia, and written informed consent was obtained from the children's parents or guardians.

\section{Wheezing and atopy definitions}

Wheezing was defined as four or more episodes of wheeze associated with cough, shortness of breath so intense as to interrupt sleep, each lasting at least three days, and treatment for asthma medication by a doctor in the past 12 months.

Atopy was defined by the presence of serum IgE antibodies $\geq 0.35 \mathrm{kU} / \mathrm{L}$ against at least one of the following allergenic preparations: Dermatophagoides pteronyssinus, Blomia tropicalis, and a mixture of allergenic foods commonly consumed by children (milk, ovalbumin and peanuts).

\section{Identification and quantification of helminthic eggs in stool samples and diarrhoea}

Faecal samples were analysed by a sedimentation method [12] and by the Kato-Katz's thick-smear technique [13] for detecting and counting helminths (T. trichiura, A. lumbricoides, hookworm, and Schistosoma mansoni) eggs. Because only a few children were infected with $S$. mansoni and hookworms, these parasites were not considered in the analysis. Children were deemed infected when at least one faecal sample tested was positive for the helminths of interest. The number of days of diarrhoea was obtained in the follow-up period.

\section{$\lg \mathrm{E}$ antibody quantification}

IgE antibodies against common childhood foods, D. pteronyssinus, B. tropicalis, and A. lumbricoides were 
measured using the Immunocap System IgE FEIA (Pharmacia, Upsala, Sweden) according to the manufacturer's instructions. Serum samples containing $\geq 0.35 \mathrm{kU} / \mathrm{L}$ or more of IgE antibodies were considered positive. These allergens were chosen based on previous observations, in paediatric clinics in Salvador, that they are the most common sensitising agents in young children in this city. These mites are also the most common sensitising agents in older children in this city [9].

\section{Statistical analysis}

The work design was cross-sectional, for studying wheezing and atopy (outcomes) in early childhood, nested in a cohort study of childhood diarrhoea. The variables analysed for their association with the outcomes were: sex; age; parental asthma; maternal literacy; presence of a septic system in the house; infection with A. lumbricoides or T. trichiura (as indicated not only by the presence of eggs in the stool but also by their numbers) and presence of anti-A. lumbricoides IgE antibodies. Occurrence of diarrhoea was presented as incidence data. Logistic univariate analysis was performed to compare each variable with the studied outcomes (wheezing and specific IgE) by calculating odds ratios [ORs and 95\% confidence interval]. To choose whether it would be included in the final logistic regression model, a variable that was not statistically significant in the univariate analysis was tested separately. If this variable continued to be not significant, it was removed from the model, while if it became significant, it was retained. All variables were retested until only significant risk factors and a priori variables remained. Because a sub-sample was taken from the 682 studied children to be tested for specific IgE antibodies, the Pearson $\mathrm{Chi}^{2}$ test was used to analyze possible differences between the sub-group of the study population that was tested for IgE antibodies (283 children) and the sub-group that was not tested (399 children). Since the children were clustered in sentinel areas, the data were adjusted by the sentinel areas in the preliminary analysis, using multivariate logistic analyses, to avoid a clustering effect. However, as no difference among sentinel areas was observed, this variable was dropped from the final analysis. The associations between all variables and wheezing or atopy were finally investigated using a multivariate logistic regression model that adjusted for the variables mentioned above. The Spearman's linear correlation coefficient between $A$. lumbricoides eggs in stool and the serum concentration of anti-A. lumbricoides IgE antibodies was calculated.

\section{Results}

The ISAAC phase I questionnaire was administered to 682 children and specific IgE measurements were performed on the sera of 283 of these children. Comparisons among those tested for IgE antibodies and among those in the untested group showed that the frequencies of all studied variables were similar between the two groups ( $p>0.05$ ), except for the incidence of diarrhoea $\geq 6$ days, which was slightly lower in the tested group than in the untested group $(35.1 \%$ and $39.5 \%$ respectively; $\mathrm{p}=0.02$; data not shown).

Table 1 shows the results of univariate and multivariate analyses of associations between wheezing and several variables (sex, age, maternal literacy, presence of a septic system, A. lumbricoides infection, T. trichiura infection, and incidence of diarrhoea) in the 682 studied children. No associations were identified between wheezing and age or A. lumbricoides infection. Males demonstrated the highest frequency of wheezing over the past 12 months, as shown by multivariate analysis [adjusted $\mathrm{OR}=1.55 ; \mathrm{CI}=1.12 ; 2.14$ ]. On the other hand, maternal literacy was found to be negatively associated with wheezing by both univariate and multivariate analyses, but this association was statistically significant only in the univariate analysis $[\mathrm{OR}=0.61$; $\mathrm{CI}=$ $0.40 ; 0.92]$. The lack of a household connection to the sewer system was associated with high frequency of wheezing, as shown by univariate and multivariate analyses $[\mathrm{OR}=1.47$; $\mathrm{CI}=1.08 ; 2.01$; adjusted $\mathrm{OR}=1.43$; CI $=1.04 ; 1.97]$. T. trichiura infection was also positively associated with wheezing by both analyses $[\mathrm{OR}=2.99$; $\mathrm{CI}=1.85 ; 4.84$; adjusted $\mathrm{OR}=2.60 ; \mathrm{CI}=1.54 ; 4.38]$, while the number of days of diarrhoea greater than six was positively associated with wheezing by both analyses, but this association was statistically significant only by univariate analysis $[\mathrm{OR}=1.58 ; \mathrm{CI}=1.04 ; 2.40$; adjusted $\mathrm{OR}=1.40 ; \mathrm{CI}=0.89-2.21]$.

Table 2 demonstrates that of the 283 children who were examined for IgE antibodies against aeroallergens and food allergens, 48.2\% had circulating IgE antibodies $\geq 0.35 \mathrm{kU} / \mathrm{L}$ and $10.0 \%$ had levels $\geq 3.5 \mathrm{kU} / \mathrm{L}$ against at least one of these allergens. The most frequent antiallergen IgE antibody detected was anti-B. tropicalis (36.1\%), followed by anti-food (23.9\%) and anti-D. pteronyssinus (19.3\%). Anti-A. lumbricoides IgE antibodies occurred in $35 \%$ of the samples and their levels did not correlate with the number of $A$. lumbricoides eggs found in the stool (Spearman's linear correlation coefficient: $r$ $=0.05 ; \mathrm{p}=0.255)$. In fact, 22 out of $53(41.5 \%)$ children in whose stools $A$. lumbricoides eggs were detected, had no serum IgE antibodies against this worm antigens.

In the subgroup of children which was positive for circulating anti-allergen IgE antibodies, positive associations were found between wheezing over the past 12 months and $T$. trichuris infection in both brute $[\mathrm{OR}=$ 2.69; $\mathrm{CI}=1.07 ; 6.77$ ] and adjusted analyses [OR = 3.07; $\mathrm{CI}=1.00 ; 9.43]$. Anti-A. lumbricoides IgE antibody levels 
Table 1 Univariate and multivariate analyses of the association of reported wheezing over the past 12 months with gender, age, intestinal helminthic infection, and diarrhoea in the studied population

\begin{tabular}{|c|c|c|c|c|c|}
\hline \multirow{3}{*}{ Variables } & \multicolumn{5}{|c|}{ Wheezing } \\
\hline & $N=682$ & Yes (257) & No (425) & OR & Adjusted OR \\
\hline & n (\%) & n (\%) & $\mathrm{N}(\%)$ & {$[95 \% \mathrm{Cl}]$} & {$[95 \% \mathrm{Cl}]$} \\
\hline \multicolumn{6}{|l|}{ Gender } \\
\hline Female & $317(46.5)$ & $100(31.5)$ & $217(68.5)$ & $1^{\#}$ & 1 \\
\hline Male & $365(53.5)$ & $157(43.0)$ & $208(57.0)$ & $1.64[1.20 ; 2.24]$ & $1.55[1.12 ; 2.14]$ \\
\hline \multicolumn{6}{|l|}{ Age (months) } \\
\hline 19 to 50 & $326(47.8)$ & $120(36.8)$ & $206(63.2)$ & 1 & 1 \\
\hline 0 to 18 & $356(52.2)$ & $137(38.5)$ & $219(61.5)$ & $1.07[0.79 ; 1.46]$ & $1.07[0.76 ; 1.51]$ \\
\hline \multicolumn{6}{|l|}{ Maternal literacy } \\
\hline Illiterate/primary & $159(23.3)$ & $71(44.7)$ & $88(55.3)$ & 1 & 1 \\
\hline Secondary (incomplete) & $278(40.8)$ & $106(38.1)$ & $172(61.9)$ & $0.76[0.51 ; 1.13]$ & $0.79[0.53 ; 1.20]$ \\
\hline Secondary (complete) & $245(35.9)$ & $80(32.7)$ & $165(67.3)$ & $0.61[0.40 ; 0.92]$ & $0.72[0.47 ; 1.11]$ \\
\hline \multicolumn{6}{|l|}{ Sewer system } \\
\hline Yes & $341(50.0)$ & $113(33.1)$ & $228(66.9)$ & 1 & 1 \\
\hline No & $341(50.0)$ & $144(42.2)$ & $197(57.8)$ & $1.47[108 ; 2.01]$ & $1.43[1.04 ; 1.97]$ \\
\hline \multicolumn{6}{|l|}{ T. trichiura eggs } \\
\hline No & $602(88.3)$ & $208(34.6)$ & $394(65.4)$ & 1 & 1 \\
\hline Yes & $80(11.7)$ & $49(61.2)$ & $31(38.8)$ & $2.99[1.85 ; 4.84]$ & $2.60[1.54 ; 4.38]$ \\
\hline \multicolumn{6}{|l|}{ A. lumbricoides eggs } \\
\hline No & $544(79.8)$ & $196(36.0)$ & $348(64.0)$ & 1 & 1 \\
\hline Yes & $138(20.2)$ & $61(44.2)$ & 77 (55.8) & $1.41[0.93 ; 2.05]$ & $1.09[0.71 ; 1.66]$ \\
\hline \multicolumn{6}{|l|}{ Days with diarrhoea } \\
\hline None & $157(23.0)$ & $50(31.8)$ & $107(68.2)$ & 1 & 1 \\
\hline$<6$ days & $273(40.0)$ & $100(36.6)$ & $173(63.4)$ & $1.24[0.82 ; 1.88]$ & $1.21[0.79 ; 1.87]$ \\
\hline$\geq 6$ days & $252(37.0)$ & $107(42.5)$ & $145(57.5)$ & $1.58[1.04 ; 2.40]$ & $1.40[0.89 ; 2.21]$ \\
\hline
\end{tabular}

\# Class reference of the variable. Bold numbers are statistically significant at 0.05 .

were positively associated with wheezing in these atopic children, with borderline non-significance in the univariated $[\mathrm{OR}=1.89 ; \mathrm{CI}=0.93 ; 3.84]$ and significantly associated in the multivariate analyses [adjusted $\mathrm{OR}=2.01 ; \mathrm{CI}=1.00 ; 4.50]$ (Table 3 ). Wheezing in nonatopic children was positive but not significantly associated with $T$. trichiura infection in univariate and multivariate analyses $[\mathrm{OR}=2.77 ; \mathrm{CI}=0.88 ; 8.76$; adjusted $\mathrm{OR}=2.45 ; \mathrm{CI}=0.70 ; 8.53]$ and not associated with $A$. lumbricoides infection $[\mathrm{OR}=1.17 ; \mathrm{CI}=0.48 ; 2.86$; adjusted $\mathrm{OR}=0.76 ; \mathrm{CI}=0.27 ; 2.11]$, but was positive and statistically associated with anti-A. lumbricoides IgE $[\mathrm{OR}=2.80 ; \mathrm{CI}=1.13 ; 6.94 ;$ adjusted $\mathrm{OR}=3.07 ; \mathrm{CI}=$ 1.13;8.35] (Table 4).

The associations between the studied variables and atopy (defined as the presence of serum IgE antibodies $\geq 0.35 \mathrm{kU} / \mathrm{L}$ against at least one of the studied allergens) are shown in Table 5 . The presence of $A$. lumbricoides eggs in the stool was not associated with atopy by either the univariate or the multivariate analysis $[\mathrm{OR}=1.17$; $\mathrm{CI}=0.65 ; 2.13$; adjusted $\mathrm{OR}=0.64 ; \mathrm{CI}=0.30 ; 1.39]$, while there was an association of anti-A. lumbricoides

Table 2 Frequencies of anti-allergen and anti-A. lumbricoides serum IgE antibodies in the studied 283 pre-school-aged children

\begin{tabular}{|c|c|c|}
\hline \multirow[t]{3}{*}{ IgE antibodies against } & \multicolumn{2}{|c|}{ Antibody concentration } \\
\hline & $\geq 0.35 \mathrm{kU} / \mathrm{L}$ & $\geq 3.5 \mathrm{kU} / \mathrm{L}$ \\
\hline & n (\%) & n (\%) \\
\hline Common childhood foods & $67(23.9)$ & $7(2.5)$ \\
\hline D. pteronyssinus & $54(19.3)$ & $8(2.9)$ \\
\hline B. tropicalis & $101(36.1)$ & $20(7.1)$ \\
\hline Common childhood foods or B. tropicalis or D. pteronyssinus & $135(48.2)$ & $28(10.0)$ \\
\hline A. lumbricoides & $99(35.4)$ & $25(8.9)$ \\
\hline
\end{tabular}


Table 3 Univariate and multivariate analyses of the association of wheezing over the past 12 months with intestinal helminthic infections, anti-A. lumbricoides IgE antibodies and diarrhoea in 135 atopic children

\begin{tabular}{|c|c|c|c|c|c|}
\hline \multirow[b]{2}{*}{ Variables } & \multicolumn{4}{|c|}{ Wheezing in atopics* } & \multirow[b]{2}{*}{$\begin{array}{c}\text { Adjusted } * * \text { OR } \\
{[95 \% \mathrm{Cl}]}\end{array}$} \\
\hline & $\begin{array}{l}\mathrm{N}=135 \\
\mathrm{n}(\%)\end{array}$ & $\begin{array}{l}\text { Yes (55) } \\
\text { n (\%) }\end{array}$ & $\begin{array}{l}\text { No (80) } \\
\text { n (\%) }\end{array}$ & $\begin{array}{c}\text { OR } \\
{[95 \% \mathrm{Cl}]}\end{array}$ & \\
\hline \multicolumn{6}{|l|}{ T. trichuris } \\
\hline No & $112(83.0)$ & $41(36.6)$ & $71(63.4)$ & $1^{\#}$ & 1 \\
\hline Yes & $23(17.0)$ & $14(60.9)$ & $9(39.1)$ & $2.69[1.07 ; 6.77]$ & $3.07[1.00 ; 9.43]$ \\
\hline \multicolumn{6}{|l|}{ Ascaris } \\
\hline No & $108(80.0)$ & $44(40.7)$ & $64(59.3)$ & 1 & 1 \\
\hline Yes & $27(20.0 \%)$ & $11(40.7)$ & $16(59.3)$ & $1.00[0.42 ; 2.36]$ & $0.44[0.15 ; 1.32]$ \\
\hline \multicolumn{6}{|c|}{ Anti-Ascaris $\lg \mathrm{E}$} \\
\hline$<0.35 \mathrm{kU} / \mathrm{L}$ & $59(43,7)$ & $19(32,2)$ & $40(67,8)$ & & \\
\hline$\geq 0.35 \mathrm{kU} / \mathrm{L}$ & $76(56,3)$ & $36(47,4)$ & $40(52,6)$ & $1,89[0,93 ; 3,84]$ & $2.01[1.00 ; 4.50]$ \\
\hline \multicolumn{6}{|l|}{ Diarrhoea } \\
\hline None & $27(20.0)$ & $9(33.3)$ & $18(66.7)$ & 1 & 1 \\
\hline$<6$ days & $59(43.7)$ & $21(35.6)$ & $38(64.4)$ & $1.10[0.42 ; 2.89$ & $0.97[0.35 ; 2,70]$ \\
\hline$\geq 6$ days & 49 (36.3) & $25(51.0)$ & $24(49.0)$ & $2.08[0.78 ; 5.53]$ & $1.62[0.53 ; 4.89]$ \\
\hline
\end{tabular}

*Atopy defined as the presence of serum IgE antibodies against at least one of the following allergens: D. pteronyssinus, B. tropicalis, mlk, ovalbumin, and peanuts.

**Adjusted for gender, age, T. trichiura eggs, A. lumbricoides eggs, days with diarrhoea and anti-Ascaris lgE.

\# Class reference of the variable.

Bold numbers are statistically significant at 0.05 .

IgE antibodies with this outcome by both types of analyses $[\mathrm{OR}=7.00 ; \mathrm{CI}=4.00 ; 12.25$; adjusted $\mathrm{OR}=7.29$; $\mathrm{CI}=3.90 ; 13.64]$. The presence of $T$. trichiura eggs in the stool was also positively associated with atopy in both analyses but it was statistically significant only in the univariate analysis $[\mathrm{OR}=2.13 ; \mathrm{CI}=1.03 ; 4.40$; adjusted $\mathrm{OR}=1.52 ; \mathrm{CI}=0.66-3.50]$. Reported wheezing over the previous 12 months and the occurrence of diarrhoea was not associated with atopy by either univariate or multivariate analyses. The A. lumbricoides and T. trichiura egg burdens of these children were low to moderate, according to WHO cut-offs [14], and no

Table 4 Univariate and multivariate analyses of the association of wheezing over the past 12 months with intestinal helminthic infections, anti-A. lumbricoides IgE antibodies and diarrhoea in 148 non-atopic children

\begin{tabular}{|c|c|c|c|c|c|}
\hline \multirow[t]{3}{*}{ Variables } & \multicolumn{5}{|c|}{ Wheezing in non-atopics* } \\
\hline & $N=148$ & Yes (47) & No (101) & OR & Adjusted** OR \\
\hline & $\mathrm{n}(\%)$ & n (\%) & n (\%) & {$[95 \% \mathrm{Cl}]$} & {$[95 \% \mathrm{Cl}]$} \\
\hline \multicolumn{6}{|l|}{ T. trichuris } \\
\hline No & $135(91.2)$ & $40(29.6)$ & $95(70.4)$ & $1^{\#}$ & 1 \\
\hline Yes & $13(8.8)$ & $7(53.8)$ & $6(46.2)$ & $2.77[0.88 ; 8.76]$ & $2.45[0.70 ; 8.53]$ \\
\hline \multicolumn{6}{|l|}{ Ascaris } \\
\hline No & $122(82.4)$ & $38(31.1)$ & $84(68.9)$ & 1 & 1 \\
\hline Yes & $26(17.6)$ & $9(34.6)$ & $17(65.4)$ & $1.17[0.48 ; 2.86]$ & $0.76[0.27 ; 2.11]$ \\
\hline \multicolumn{6}{|c|}{ Anti-Ascaris lgE } \\
\hline$<0.35 \mathrm{kU} / \mathrm{L}$ & $125(84.5)$ & $35(28.0)$ & $90(72.0)$ & & \\
\hline$\geq 0.35 \mathrm{kU} / \mathrm{L}$ & $23(15.5)$ & $12(52.2)$ & $11(47.8)$ & $2.80[1.13 ; 6.94]$ & $3.07[1.13 ; 8.35]$ \\
\hline \multicolumn{6}{|l|}{ Diarrhoea } \\
\hline None & $23(15.5)$ & 7 (30.4) & $16(69.6)$ & 1 & 1 \\
\hline$<6$ days & $62(41.9)$ & $18(29.0)$ & $44(71.0)$ & $0.93[0.33 ; 2.66]$ & $1.17[0.39 ; 3.53]$ \\
\hline$\geq 6$ days & $63(42.6)$ & $22(34.9)$ & $41(65.1)$ & $1.23[0.44 ; 3.43]$ & $1.79[0.55 ; 5.78]$ \\
\hline
\end{tabular}

*Atopy defined as the presence of serum IgE antibodies against at least one of the following allergens: D. pteronyssinus, B. tropicalis, mlk, ovalbumin, and peanuts.

**Adjusted for gender, age, T. trichiura eggs, A. lumbricoides eggs and days with diarrhoea.

\# Class reference of the variable.

Bold numbers are statistically significant at 0.05 . 
Table 5 Univariate and multivariate analyses of the association of atopy with gender, age, intestinal helminthic infections, and diarrhoea in the subpopulation tested for serum anti-allergen IgE antibodies

\begin{tabular}{|c|c|c|c|c|c|}
\hline \multirow[t]{3}{*}{ Variables } & \multirow{3}{*}{$\begin{array}{r}N=283 \\
n(\%)\end{array}$} & \multicolumn{4}{|c|}{ Atopy* } \\
\hline & & Yes (135) & No (148) & OR & ${ }^{\# \#}$ Adjusted OR \\
\hline & & n (\%) & n (\%) & {$[95 \% \mathrm{Cl}]$} & {$[95 \% \mathrm{Cl}]$} \\
\hline \multicolumn{6}{|l|}{ Gender } \\
\hline Female & $129(45.6)$ & $57(44.2)$ & $72(55.8)$ & $1^{\#}$ & 1 \\
\hline Male & $154(54.4)$ & $78(50.6)$ & $76(49.4)$ & $1.30[0.81 ; 2.07]$ & $1.30[0.76 ; 2.24]$ \\
\hline \multicolumn{6}{|l|}{ Age (months) } \\
\hline 19 a 48 & $137(48.4)$ & $76(55.5)$ & $61(44.5)$ & 1 & 1 \\
\hline 0 a 18 & $146(51.6)$ & $59(40.4)$ & 87 (59.6) & $0.54[0.34 ; 0.87]$ & $0.64[0.36 ; 1.15]$ \\
\hline \multicolumn{6}{|l|}{ Maternal literacy } \\
\hline Illiterate/primary & $60(21.2)$ & $32(53.3)$ & $28(46.7)$ & 1 & 1 \\
\hline Secondary incomplete & $129(45.6)$ & $57(44.2)$ & $72(55.8)$ & $0.69[0.37 ; 1.28]$ & $0.84[0.41 ; 1.70]$ \\
\hline $\begin{array}{l}\text { Secondary complete } \\
\text { or more }\end{array}$ & $94(33.2)$ & $46(48.9)$ & $48(51.1)$ & $0.84[0.44 ; 1.60]$ & $1.16[0.55 ; 2.45]$ \\
\hline \multicolumn{6}{|l|}{ Sewer system } \\
\hline Yes & $141(49.8)$ & $62(44.0)$ & $79(56.0)$ & 1 & 1 \\
\hline No & $142(50.2)$ & $73(51.4)$ & 69 (48.6) & $1.35[0.84 ; 2.15]$ & $1.40[0.82 ; 2.37]$ \\
\hline \multicolumn{6}{|l|}{ Trichuris eggs } \\
\hline No & $247(87.3)$ & $112(45.3)$ & $135(54.7)$ & 1 & 1 \\
\hline Yes & $36(12.7)$ & $23(63.9)$ & $13(36.1)$ & $2.13[1.03 ; 4.40]$ & $1.52[0.66 ; 3.50]$ \\
\hline \multicolumn{6}{|l|}{ Ascaris eggs } \\
\hline No & $230(81.3)$ & $108(47.0)$ & $122(53.0)$ & 1 & 1 \\
\hline Yes & $53(18.7)$ & $27(50.9)$ & $26(49.1)$ & $1.17[0.65 ; 2.13]$ & $0.64[0.30 ; 1.39]$ \\
\hline \multicolumn{6}{|l|}{ Anti-Ascaris lgE } \\
\hline$<0.35 \mathrm{KU} / \mathrm{L}$ & $184(65,0)$ & $59(32,1)$ & $125(67,9)$ & 1 & 1 \\
\hline$\geq 0.35 \mathrm{KU} / \mathrm{L}$ & $99(35,0)$ & $76(76,8)$ & $23(23,2)$ & 7.00 [4.00;12.25] & $7.29[3.90 ; 13.64]$ \\
\hline \multicolumn{6}{|l|}{$\begin{array}{l}\text { Wheezing in the } \\
\text { past } 12 \text { months }\end{array}$} \\
\hline No & $181(64.0)$ & $80(44.2)$ & $101(55.8)$ & 1 & 1 \\
\hline Yes & $102(36.0)$ & $55(53.9)$ & $47(46.1)$ & $1.48[0.91 ; 2.41]$ & $1.02[0.57 ; 1.80]$ \\
\hline \multicolumn{6}{|l|}{ Days with diarrhoea } \\
\hline None & $50(17.7)$ & $27(54.0)$ & $23(46.0)$ & 1 & 1 \\
\hline$<6$ days of duration & $121(42.8)$ & $59(48.8)$ & $62(51.2)$ & $0.81[0.42 ; 1.57]$ & $0.84[0.40 ; 1.80]$ \\
\hline$\geq 6$ days of duration & 112 (39.6) & 49 (43.8) & $63(56.2)$ & $0.66[0.34 ; 1.29]$ & $0.99[0.44 ; 2.24]$ \\
\hline
\end{tabular}

*Defined as the presence of serum IgE antibodies against at least one of the following allergens: D. pteronyssinus, B. tropicalis, mlk, ovalbumin, and peanuts. ${ }^{* *}$ Adjusted for gender, age, T. trichiura eggs, A. lumbricoides eggs and days with diarrhoea.

${ }^{\#}$ Class reference of the variable.

Bold numbers are statistically significant at 0.05 .

statistical associations were found between this variable and wheezing or atopy (data not shown).

\section{Discussion}

In the present study, although $39 \%$ of the 283 studied children for IgE antibodies experienced at least one episode of severe wheezing over the past 12 months, only $10 \%$ possessed IgE antibodies against common allergens $\geq 3.5 \mathrm{kU} / \mathrm{L}$. This IgE level is considered as the threshold for developing the clinical symptoms of allergic asthma [15]. Furthermore, no association was found of wheezing with anti-allergen IgE antibody levels $\geq 0.35 \mathrm{kU} / \mathrm{L}$ (Table $5)$. Thus, most of the reported wheezing episodes were not atopy-related. Further support for this observation comes from the finding that the absence of a household connection to the sewer system increased the odds of wheezing in the multivariate analyses. This finding seems contrary to the hygiene hypothesis but reinforces the possibility of an infectious aetiology for the reported wheezing. The current study is in agreement with previous reports that most early-childhood wheezing is not related to allergy, based on data from developed countries, where this condition is mainly described associated with virus infection $[16,17]$. The finding that wheezing is more common in boys than in girls is also in accordance with previous studies [16]. 
Both A. lumbricoides and T. trichiura infections were positively associated with wheezing in the present study (in the case of $A$. lumbricoides, only when the infection was serologically defined by the presence of specific IgE antibodies). The associations were robust, even after adjustment for confounding variables in the multiple logistic regression analysis. The finding that anti-A. lumbricoides IgE antibodies increases the risk for atopy and wheezing has been reported previously in regions of low, medium, and high endemicity [18-20]. On the other hand, T. trichiura infection has not been described as positively associated with asthma or atopy in the literature, although an association of this parasite with atopic eczema has been reported [21]. Intestinal helminths induce IgE-producing, Th2 immune responses [22]. The $A$. lumbricoides infection that leads to high levels of anti-Ascaris antibodies could also promote, by a non-specific effect, higher levels of allergen-specific antibodies [23,24]. This could explain the association between this parasite specific IgE antibodies and atopic wheezing, but not with nonatopic wheezing. An explanation for this last association could be the sensitization of lung mast cells with anti-A. lumbricoides IgE antibodies and their eventual degranulation by antigens released by migrating A. lumbricoides larvae.

The presence of high levels of anti-A. lumbricoides IgE antibodies would reflect at least a partial immunity to infection, which would explain the association of wheezing with IgE antibodies and not with A. lumbricoides eggs in the stool. This immunity would therefore explain the absence of correlation between A. lumbricoides eggs in the stool and this parasite specific serum IgE antibodies, observed in this and in a previously reported study [25]. The frequency of antibody-eliciting larvae invasion should be directly proportional to poor sanitation, such as a lack of a sewage system, which was also associated with more frequent wheezing in the studied population.

In addition to association with wheezing, we identified a clear association between the presence of anti-A. lumbricoides IgE antibodies and atopy. However, as mentioned earlier, there are conflicting reports on intestinal helminthic infections decreasing, not affecting or increasing atopy and allergic symptoms [2-7], although a systematic review and meta-analysis found that $A$. lumbricoides infection was associated with a significantly increased risk of asthma [26]. The fact that A. lumbricoides eggs were not associated with wheezing and atopy, while there were strong associations of anti-A. lumbricoides IgE antibodies with these two outcomes, may explain why some previous studies relying only on the detection of helminthic eggs did not identify these associations $[4,5]$. In addition, one widely accepted hypothesis that has been put forward to explain these discrepant findings is that high worm burden and chronic helminthic infections would lead to the production of immunoregulatory cytokines and to protection against atopy and asthma, while low worm burden or recent infection would promote atopy and allergy $[5,8]$. The present data corroborate this hypothesis, since the studied children are very young and probably had been infected recently. Moreover, these children had low to moderate A. lumbricoides and T. trichiura egg burdens. It is possible that several months or years in the future, with repeated or chronic $T$. trichiura infections, the tendency would be for infection-associated regulatory cells $[27,28]$ reducing atopy. This phenomenon would account for the findings of an investigation carried out recently in Salvador by our research group [9], which showed that early infection by $T$. trichiura protected against the development of aeroallergen skin test reactivity in later childhood. This finding in older children, and the demonstration in the present report of a positive association between $T$. trichiura infection and wheezing in infants, is consistent with the acute-chronic infection hypothesis explaining different types of association between helminth infection and atopy, mentioned above.

In the present work, we have quantified parasitic eggs in faecal samples and analysed the association of worm burden with wheezing and atopy (data not shown). The absence of association between worm burden with wheezing and atopy was attributed to a low variability of parasite burdens, since all children had low to moderate egg intensity.

Unfortunatelly, anti-T. trichiura IgE antibodies could not be measured in this work, so it was not possible to study the association of IgE antibodies against this parasite with the studied outcomes, as was done for antiA. lumbricoides IgE levels. The hypothesis proposed above, however, predicts that the association of wheezing and atopy with anti- $T$. trichiura IgE antibodies should be stronger than their association with T. trichiura egg burden. The presence of a statistically significant association of $T$. trichiura infection with atopic wheezing and not with atopy, in the multivariate analysis, is not easily explained. However, it may indicate that T. trichiura infection would enhance the development of wheezing more easily in children who are more susceptible to develop lung inflammation, perhaps by stimulating ongoing allergic responses. In addition, another intriguing question remains. Since anti- $A$. lumbricoides IgE antibodies, but not $A$. lumbricoides eggs, are associated with wheezing and atopy in the studied children, why is the presence of $T$. trichiura eggs in the stool robustly associated with wheezing in the same children? One potential explanation is that helminths may differ in their susceptibility to IgE antibodies. More specifically, T. trichiura may be more resistant than $A$. lumbricoides to IgE- 
dependent effector mechanisms. Thus, the effect of T. trichiura on the immune system would enhance IgE responses in a whole, accounting for its association with atopic wheezing, without concomitantly leading to selfelimination.

\section{Conclusion}

The present results show that helminthic infection may be, in addition to respiratory tract viruses, a cause of early wheezing in small children who have been recently or lightly infected. These helminthic infections may also be involved in increasing atopy. Further investigations, based on birth-cohort or experimental animal studies, should be performed in order to clarify the role played by these parasites, their soluble antigens, or anti- parasite anti-allergen cross-reactive antibodies in the pathogenesis of atopy, asthma and other allergic disorders.

\section{List of abbreviation}

Cl: confidence interval; KU/L: kilo unit per liter; ASIGE: allergen specific immunoglobulin E antibody; ISAAC: international Study of Asthma and allergies in Childhood; OR: odds ratio; TH2: T helper cells 2; SCAALA: (Social Change, Asthma and Allergy in Latin America) research program;

\section{Conflict of interest}

All authors report no conflict of interest financial or otherwise, with the findings of this study.

\section{Authors' contributions}

NA-N has designed and wrote the manuscript; SB helped in the surveys and carried out the laboratory assays; MS has done the statistical analyses; LP-C helped in writing and reviewed the manuscript. MB has coordinated the group, conceived and reviewed the manuscript. All authors read and approved the final manuscript.

\section{Acknowledgements}

This study was conducted through the SCAALA iniciative and was funded by the WELLCOME TRUST (grant No. 072405/Z/03/Z) and by Programa Institutos Nacionais de Ciência e Tecnologia (MCT-CNPq-edital nº 015/2008). We are in debt to Dr. Sérgio S. Cunha and Dr. Rosemeire L. Fiaccone for their assistance with the statistical analyses, as well as to Dr. Renato T. Stein for critically reading the manuscript.

\section{Author details}

'Departmento de Ciências da Biointeração, Instituto de Ciências da Saúde, Universidade Federal da Bahia, Salvador, Brazil. 'Laboratório de Patologia e Biologia Interativa, Centro de Pesquisas Gonçalo Moniz, Fundação Oswaldo Cruz, Salvador, Brazil. ${ }^{3}$ Instituto de Saúde Coletiva, Universidade Federal da Bahia, Salvador, Brazil.

Received: 6 December 2009 Accepted: 23 August 2010 Published: 23 August 2010

\section{References}

1. Solé D: Epidemiological studies and their impact in children's health: international study of asthma and allergies in childhood (ISAAC). Rev Bras Saúde Mater Infant 2005, 5:261-2.

2. Yazdanbakhsh M, Kremsner PG, van Ree R: Allergy, parasites, and the hygiene hypothesis. Science 2002, 296:490-5.

3. Cooper PJ: Intestinal worms and human allergy. Parasite immunol 2004, 26:455-67.

4. Wördemann M, Diaz RJ, Heredia LM, Collado Madurga AM, Ruiz Espinosa A, Prado RC, Millan IA, Escobedo A, Rojas Rivero L, Gryseels B, Gorbea MB, Polman K: Association of atopy, asthma, allergic rhinoconjunctivitis, atopic dermatitis and intestinal helminth infections in Cuban children. Trop Med Int Health 2008, 13(2):180-6.

5. Cooper PJ, Chico ME, Vaca MG, Moncayo AL, Bland JM, Mafla E, Sanchez F, Rodrigues LC, Strachan DP, Griffin GE: Effect of albendazole treatments on the prevalence of atopy in children living in communities endemic for geohelminth parasites: a cluster-randomised trial. Lancet 2006, 367:1598-603.

6. Hagel I, Cabrera M, Hurtado MA, Sanchez P, Puccio F, Di Prisco MC, Palenque M: Infection by Ascaris lumbricoides and bronchial hyper reactivity: an outstanding association in Venezuelan school children from endemic areas. Acta Trop 2007, 103:231-41.

7. Pereira MU, Sly PD, Pitrez PM, Jones MH, Escouto D, Dias AC, Weiland SK, Stein RT: Nonatopic asthma is associated with helminth infections and bronchiolitis in poor children. Eur Respir J 2007, 29:1154-60.

8. Smits HH, Yazdanbakhsh M: Chronic helminth infections modulate allergen-specific immune responses: protection against development of allergic disorders? Ann Med 2007, 39(6):428-39.

9. Rodrigues LC, Newcombe PJ, Cunha SS, Alcantara-Neves NM, Genser B, Cruz AA, Simoes SM, Fiaccone R, Amorim L, Cooper PJ, Barreto ML, Social Change, Asthma and Allergy in Latin Americal: Early infection with Trichuris trichiura and allergen skin test reactivity in later childhood. Clin Exp Allergy 2008, 38:1769-77.

10. Genser B, Strina A, Teles CA, Prado MS, Barreto ML: Risk Factors for Childhood Diarrhea Incidence: Dynamic Analysis of a Longitudinal Study. Epidemiology 2006, 17(6):658-67.

11. Barreto ML, Genser B, Strina A, Teixeira MG, Assis AM, Rego RF, Teles CA, Prado MS, Matos SM, Santos DN, dos Santos LA, Cairncross S: Effect of citywide sanitation programme on reduction in rate of childhood diarrhoea in northeast Brazil: assessment by two cohort studies. Lancet 2007, 370(9599):1622-8.

12. Hoffman WA, Pons JA, Janer JL: The sedimentation concentration method in schistosomiasis mansoni. Puerto Rico J publ Hlth 1934, 9:281-98.

13. Katz $\mathrm{N}$ : A device for quantitative stool thick-smear technique in Schistosomiasis mansoni. Rev Inst Med Trop Sao Paulo 1972, 14:397-400.

14. WHO, Prevention and control of intestinal parasitic infetions. Geneva: WHO, technical reports Series b 1987.

15. Wickman M, Ahlstedt S, Lilja G, Hamsten MH: Quantification of IgE antibodies simplifies the classification of allergic diseases in 4-yaer-old children. A report from the birth cohort study - BAMSE. Pediatr Allergy Immunol 2003, 14:441-47.

16. Wright AL: Epidemiology of asthma and recurrent wheeze in childhood. Clin Rev Allergy Immunol 2002, 22:33-44.

17. Heymann PW, Carper HT, Murphy DD, Platts-Mills TA, Patrie J, McLaughlin AP, Erwin EA, Shaker MS, Hellems M, Peerzada J, Hayden FG, Hatley TK, Chamberlain R: Viral infections in relation to age, atopy, and season of admission among children hospitalized for wheezing. J Allergy Clin Immunol 2004, 114:239-47.

18. Hunninghake GM, Soto-Quiros ME, Avila L, Ly NP, Liang C, Sylvia JS, Klanderman BJ, Silverman EK, Celedón JC: Sensitization to Ascaris lumbricoides and severity of childhood asthma in Costa Rica. J Allergy Clin Immunol 2007, 119:654-61.

19. Obihara CC, Beyers N, Gie RP, Hoekstra MO, Fincham JE, Marais BJ, Lombard CJ, Dini LA, Kimpen JL: Respiratory atopic disease, Ascarisimmunoglobulin $\mathrm{E}$ and tuberculin testing in urban South African children. Clin Exp Allergy 2006, 36:640-48.

20. Takeuchi H, Zaman K, Takahashi J, Yunus M, Chowdhury HR, Arifeen SE, Baqui A, Wakai S, Iwata T: High titre of anti-Ascaris immunoglobulin E associated with bronchial asthma symptoms in 5-year-old rural Bangladeshi children. Clin Exp Allergy 2008, 38:276-82.

21. Haileamlak A, Dagoye D, Williams H, Venn AJ, Hubbard R, Britton J, Lewis SA: Early life risk factors for atopic dermatitis in Ethiopian children. J Allergy Clin Immunol 2005, 115:370-76.

22. Jankovic D, Steinfelder S, Kullberg MC, Sher A: Mechanisms underlying helminth- induced Th2 polarization: default, negative or positive pathways? Chem Immunol Allergy 2006, 90:65.

23. Acevedo N, Sánchez J, Erler A, Mercado D, Briza P, Kennedy M, Fernandez A, Gutierrez M, Chua KY, Cheong N, Jiménez S, Puerta L, Caraballo L: IgE cross-reactivity between Ascaris and domestic mite allergens: the role of tropomyosin and the nematode polyprotein ABA-1. Allergy 2009, 64(11):1635-43. 
24. Santos AB, Rocha GM, Oliver C, Ferriani VP, Lima RC, Palma MS, Sales VS, Aalberse RC, Chapman MD, Arruda LK: Cross-reactive IgE antibody responses to tropomyosins from Ascaris lumbricoides and cockroach J Allergy Clin Immunol 2008, 121(4):1040-1046.

25. Fincham JE, Markus MB, van der Merwe L, Adams VJ, van Stuijvenberg ME, Dhansay MA: Ascaris, co-infection and allergy: the importance of analysis based on immunological variables rather than egg excretion. Trans $R$ Soc Trop Med Hyg 2007, 101:680-82.

26. Leonardi-Bee J, Pritchard D, Britton J: Asthma and current intestinal parasite infection: systematic review and meta-analysis. Am J Respir Crit Care Med 2006, 174:514-23.

27. A, Zagierski M, Liberek A, Aleksandrowicz E, Korzon M, Krzykowski G, Kamińska B, Szlagatys-Sidorkiewicz AMarek: TGF-beta(1), IL-10 and IL-4 in colostrum of allergic and nonallergic mothers. Acta Biochim 2009, 56(3):411-4.

28. van den Biggelaar AH, van Ree R, Rodrigues $L C$, Lell B, Deelder AM, Kremsner PG, Yazdanbakhsh M: Decreased atopy in children infected with Schistosoma haematobium: a role for parasite-induced interleukin-10. Lancet 2000, 356:1723-2732.

doi:10.1186/1465-9921-11-114

Cite this article as: Alcântara-Neves et al:: The presence of serum antiAscaris lumbricoides IgE antibodies and of Trichuris trichiura infection are risk factors for wheezing and/or atopy in preschool-aged Brazilian children. Respiratory Research 2010 11:114.

\section{Submit your next manuscript to BioMed Central and take full advantage of:}

- Convenient online submission

- Thorough peer review

- No space constraints or color figure charges

- Immediate publication on acceptance

- Inclusion in PubMed, CAS, Scopus and Google Scholar

- Research which is freely available for redistribution

Submit your manuscript at www.biomedcentral.com/submit 